\title{
Stress Placement in English Quadri-Syllabic and Five-Syllabic Suffixed Words and Their Roots by Pashto Speakers in Khyber Pakhtunkhwa of Pakistan
}

\author{
Afzal Khan ${ }^{1}$, Inayat Ullah ${ }^{1} \&$ Aziz Ullah Khan ${ }^{1}$ \\ ${ }^{1}$ Department of Humanities (English), Air University, Islamabad, Pakistan \\ Correspondence: Afzal Khan, Department of Humanities (English), Air University, Islamabad, Pakistan. E-mail: \\ afzalenghu@gmail.com
}

Received: June 20, 2017 Accepted: July 25, 2017 Online Published: September 25, 2017

doi:10.5539/ijel.v7n6p123 URL: http://doi.org/10.5539/ijel.v7n6p123

\begin{abstract}
This research study investigates the pattern of English (primary) word stress in quadri-syllabic and five-syllabic suffixed words and their roots by Pashto speakers in Khyber Pakhtunkhwa of Pakistan and the effect of suffixation on stress placements. These suffixes in English language are called shifters which shift strong stress to the antepenultimate (third from the last), penultimate (second from the last), and ultimately (last) syllables, as well as those suffixes that do not shift strong stress to other syllables. The data was collected from sixteen Pashto language native speakers in Khyber Pakhtunkhwa Pakistan, by way of recording their oral-reading of a card that contained the selected words. The findings of this study indicate that primary stress pattern varies among quadri-syllabic, and five-syllabic, suffixed words. The three types of suffixes in English language assert different degrees of effect on subjects stress placement, which can influence the amount of correct productions by the subjects. Actually, the suffixes "cial" or "tial" and "ic" state a great effect on subjects primary stress placement, because the subjects were capable of generating the shift in primary stress in penultimate syllable. Unlike the greater number of incorrect productions in "tory" and "ity" suffixed words, the subjects were sensitive to the change of stress pattern, which assists a great number of correct productions in "cial" or "tial" and "ic" suffixed words. The findings disclose the fact that there was extreme unawareness of the strong stress shifting effect by Pashto speakers in Khyber Pakhtunkhwa, which further needed more attention.
\end{abstract}

Keywords: stress placement, quadri-syllabic and Five-syllabic suffixed words, Pashto speakers, Khyber Pakhtunkhwa Pakistan

\section{Introduction}

When we speak, our speech is not monotonous; it has its own rise and fall which ultimately render understanding in context of sounds. There has certain aspect of speech sounds that allow the listener understand the speech and thus communicate successfully. In the locus, of this communicative aspect of speech stands a syllable. Krcmova (2007) defines a syllable as "the easiest and the most immediate articulatory unit of functional elements of speech that is satisfactory for communication". Roach (1991) regards a syllable phonetically as "consisting of a center which has little or no obstruction to airflow and which sounds comparatively loud; before and after this center (beginning and end of the syllable) there will be greater obstruction and acoustic resonance" (Roach, 1991, p. 67).

Stress is defined as "the use of extra respiratory energy during a syllable" by Ladefoged (2001, p. 276). Further, Teschner \& Whitley ((2004, p. 270) define syllable as "the greater prominence or loudness that a syllable exhibits within a word, in at least two degrees: strong/weak (or primary/secondary)". According to Kingdon (1958), there are two types of stress, namely, word (lexical) Stress and sentence (syntactical) stress. Word stress is defined as "the relative degree of force used in pronouncing the different syllables of a word of more than one syllable".

There are some salient features that give prominence to primary word stress. It would be clear when we look at primary word stress from two possible angles. Firstly, from the perceptual point of view and secondly, from the point of production. Regarding production Roach believes that the greater muscular energy implied for stressed syllables as opposed to unstressed syllables in a word. From the perceptual point of view, it is prominence in syllables (1991, pp. 85-86). About the prominence in syllables, all phoneticians agree, that what make a syllable prominent are the following factors or components responsible for prominence in syllables: loudness, length, pitch, 
and a quality of a vowel. It is important to say that these factors complement each other in creating prominence in stressed syllables. They do not work in isolation; rather they are part and parcel to one another in speech. Therefore, it is sometimes difficult to distinguish between them as they are all for one, and one for all in speech production and perception. However, not all of the factors are either equally important or always present but some of them at a time can render intelligibility.

Primary word stress, as the name signifies, is the placement of strong stress on certain syllables within a given word. Some words carry no word stress (mostly in the case of monosyllabic words) on the other hand some words has multiple stresses, with varying degrees of strength.

This research study investigated English primary stress pattern in Quadri-syllabic, and Five-syllabic stems and their roots, of Khyber Pakhtunkhwa English speaking students, whose first language is Pashto. Besides, this study will also demonstrate whether the addition of different types of suffixes in multi-syllables words will assert an effect upon stress placement of Khyber Pakhtunkhwa Pashto speaking students. The analysis of this study is consisted in two main parts, English primary stress patterns produced by the subjects and the effect of suffixation on patterns of primary stress placements. The first part of this research is further sub-divided into (1) Primary stress pattern in Quadri-syllabic stems and their roots, (2) Primary stress pattern in Five-syllabic stems and their roots. The second part of the this study is divided into three sub-sections by the types of suffixes involved, namely (1) "tory" and "cy" stems of suffixes (2) "rious" and "ity" stems of suffixes and (3) "cial" or "tial" and "ic" stems of suffixes.

\section{Literature Review}

Stress in English language is a very complex phenomenon. For the last few decades, many scholars and researchers have been occupied with continuous efforts to identify the underlying rules for the placement of stress. A reputed pioneer in this field was Robert Kingdon, who put forth a suffix-based approach. He claimed that adding a suffix to a root influence, the stress placement in words. He also holds the view that the stress placement in a word also depends largely on the origin of that words, that is, where from the word had originated; Latin, Greek, Scandinavian, or English type of a word, or rather compounds. Although his contribution towards stress placement in English language nevertheless suffers from the fact that he did not distinguish between strong and weak syllables.

The suffixes-based approach of English primary stress placement is generally accepted nowadays. Likewise, it is also generally acknowledged that if there are no suffixes attached to the roots, it depends on the properties of various syllables where the stress falls (Fudge, 1984, p. 12).

Fudge (1984) merged parts of all renowned scholars like Kingdon's, Chomsky, and Halle's approaches and produced an extensive rationalization, where primary stress falls. His approach is based on counting back the number of syllables from the end of an English word which he calls the "stressable portion". Stressable portion "is what is left of the word when certain suffixes and prefixes have been removed from it" (Fudge, 1984, p. 17). After the suffixes and prefixes are removed from the word, it depends on the structure of the stressable portion.

Tremblay (2008) conducted a research on Prosodic constraints in the acquisition of English primary stress placement in words by French Canadian L2 learners. This study deals with English Primary stress placement in English words by Second Language learners, investigating English primary stress on words by French Canadian L2 learners of English. Primary Word stress is a particularly relevant linguistic phenomenon, because it reflects the shape of the prosodic structure that underlies L2 learner's production of L2 words. Since Canadian French and English differ extensively in their prosodic or supra-segmental structure, they provide an ideal constellation of native language (L1) and target language for looking into this phenomenon.

It is observed that native speakers of Canadian French follow two different developmental paths in the learning of English primary stress placement in words, one which yields a target-like prosodic structure and one which does not. It is further argued that it is difficult for L2 learners to recover from the non-target-like prosodic grammar they have acquired. Analyzing the learning stages that L2 learners follow during second language acquisition, when learning total abstract L2 prosodic representations is important for understanding how L2 learning takes place in term of primary stress placement. It unveils the ways in which the inter-language grammar is prosaically constrained at different developmental stages of L2 learners and why not all L2 learners ultimately reach target-like prosodic representations in their speech production.

Jana (2012) conducted a research study on, Stress and intelligibility: pronunciation of secondary school students of English by Czech learners. In this research study the researcher focuses on supra-segmental features of speech, namely primary word stress placement. As she has been a teacher at a Secondary School of Civil Engineering for 
three years she therefore chose to conduct a research on English primary stress placement by second language learners of Czech and its impact on students' intelligibility, as well as overall progress in their pronunciation competence. Moreover the researcher adhered to focus on the learner's pronunciation and practicing, which have a positive effect on students, resulting in their greater self-confidence in the command of English.

The reason she chose to dedicate her work solely to English primary word stress pattern by second language learners is, as significant number of scholars claimed supra-segmental features, to which primary word stress belongs, is of great importance in speakers' intelligibility. Moreover, for Czech English as second language learners especially this fact may cause considerable problems as Czech language is a syllable-timed language, while on the other hand English is a stress-timed language. Tomkova confirms the typical situation in terms of learning English as a second language by Czech students, stating that most Czech English language learners pronunciation only consists in segmental practice, neglects the dynamic character of English language and thus results in poor comprehension of authentic speech even after relatively long training Tomkova (2003).

Hence students often feel discouraged by the fact they are either not understood or more often, by their inability to understand recorded English speech, as this one is the most frequent phenomenon they have a chance to experience during English lessons. Therefore, the hypothesis of this study goes that supra-segmental features (English primary stress placement in words) of speech, stress in particular, are the most important factors concerning the intelligibility of a speaker's speech.

Bot (1996) correctly states that knowing a problem is not solving it, but this knowledge can help to increase the attention on relevant information on the input level, helping the solution of the problem. Therefore, when students are constantly exposed to wrong input, the output will definitely not be correct at all. Also, when a preliminary student is exposed to unknown words during second language learning, his tendency is to look for a pattern within his first language. Pater (1997, p. 235) also argues that "it is uncontroversial that learners of a second language, at least in the earliest stages, make use of first language rules most of the time, parameter settings, or constraints for word level primary stress placement".

\section{Methodology}

The present study is designed for experiments along with the observation of native speakers of Pashto language and their primary stress placement in English quadri-syllabic and Five-syllabic suffixed words and their roots. The experimental design is chosen in order to base the study on more scientific and reliable bases. The approaches for the study include both qualitative and quantitative approaches. The qualitative approach provided the theoretical materials for the study, which was obtained from the study of the Primary stress pattern in English language and research worked, conducted in other languages of the world. This theoretical material was supported with the observations of English language teaching experts. From this theoretical material a quantitative study based on the performance level of Pashto speakers production in primary stress placement in English words.

In qualitative approach of the study, the stress pattern of English words by different people was studied across the world. The previous works of stress pattern in English words by non-native speakers, helped us to identify the issues within the languages selected, and the issues across the language in learning the other language i.e. English as (L2) is learned with L1 background. The work was further verified in the light of the English root words and their six suffixed forms chosen for the study. Later on the issue was confirmed quantitatively through the data collected from Pashto native speakers in Khyber Pakhtunkhwa Pakistan.

When the qualitative study of root words and their stems along with the effect of suffixation in English language by L2 English learners specified the issues involved, it led us to seek the effects of the L1 (Pashto Language) primary stress placement on Pashto speakers. The approach adopted for the issue was a quantitative one, in which the data was obtained from native speakers of Pashto with English language learning background. The data for the study was obtained through scientific tools of recording, by means of MP3 Players of high quality. This quantitative approach settled the issues in the present study.

The attachments of these suffixes, that is "ity" "rious" "cial"/ "tial" "ic" "tory" and "cy" to the root words, shift the pattern of stress placement in English Quadri-syllabic and Five-syllabic words. These suffixes were selected based on their effect on shifting primary word stress placement. Suffixes "ity" and, "rious" shift primary stress placement to the antepenultimate (third from the last) syllable. Suffixes "cial" / "tial" and "ic" shift primary word stress placement to the penultimate (second-from-the-last) syllable. These two pairs of suffixes are called "shifter" (Teschner \& Whitley, 2004, p. 33). These suffixes in English language are classified as stress-shifting since "primary stress shifts whenever a "shifter" suffix is attached to the root of the word" (Teschner \& Whitley, 2004, p. 33). The final two suffixes "tory" and, "cy" are classified in English language as stress-neutral which means that they do not shift the primary stress from one syllable to another (Teschner \& Whitley, 2004, p. 33). 


\subsection{Participants}

The data was collected from a sample of sixteen participants. These participants were from seventeen to thirty years of age. These participants were selected from four different institutions. Four participants were chosen from each college. Two government and two private colleges were selected for quality sampling. These Consisted of, Government degree college Matta, Swat, Government Post Graduate, Jehanzeb College Saidu sharif Swat, Swat Public School and College (SPS) and Excelsior College Fizagat Swat. In all these institutions English was taught as a compulsory subject. All the participants were native speakers of Pashto language. They all had background knowledge of English by studying it for more than ten years in school as a compulsory subject. The medium of instruction in all these colleges and institutions was English. All these participants belonged to different localities of Khyber Pakhtunkhwa in Pakistan.

They had studied English in different institutions. The sample, selected represents nearly all the major areas in Khyber Pakhtunkhwa, where Pashto language is spoken. Some of these participants had very sound background knowledge of English language. They have been included in the study, in order to see whether their participation does make any difference or not.

\subsection{Test Material}

In order to investigate the primary stress placement in English words by Pashto speakers, 4 bi-syllabic and 28 tri-syllabic root words, while 24 Quadri-syllabic and 8 five-syllabic suffixed words were selected. These stems (32 in number) were formed by attaching the selected six affixes. These affixes are "ity" "rious" "cial" / "tial" "ic" "tory" and "cy" see appendix A and B for details.

The attachment of these affixes to the root words shifts the pattern of stress placement in English words of Quadri-syllabic, and Five-syllabic, stems.

\subsection{Data Collection Procedure}

These 32 suffixed forms and their 32 root words, in total 64 were written on cards individually, root word on one side of the card and its suffixed form on the other side of the card had written and the participants were asked to pronounce them loudly and clearly. These words were pronounced by the participants that were recorded. Each participant had to pronounce the selected word for three times.

\subsection{Data Analysis}

The data for the present study was recorded by MP3 players of high quality in order to remove ambiguities in the analysis. The data was recorded and then demonstrated through tables in result portion of the data.

The data obtained was heard with the help of the high quality speakers. The primary stress placement in all the words were transcribed and marked by the symbol of English primary stress (') and attached in tables in result portion. The primary stress placement in English root words and their suffixed forms produced by Pashto speakers were identified, by listening to the recorded data, which was obtained from the participants with Pashto background. These root words along with suffixed forms had been produced differently by different participants. Once the Root word or its stem was heard by listening time and again, the production of words by the participants was recognized in this way. The data was then further analyzed and demonstrated in different tables according to their root words and suffixed forms.

\section{Results}

The "Injury" "Victory" "Luxury" and "Labour" (Table 1) are tri-syllabic root words carrying strong stress on first syllable in these words but when the suffixes "rious" attached to these words the stress is shifted to second syllable of these words. All the subjects placed primary stress on first syllable in all these words. Which were the correct stress patterns of primary stress produced by the Participants.

Table 1. Number of productions by the subjects in Tri-syllabic root words, carry first syllable stress

\begin{tabular}{llllll}
\hline Correct stress & First syllable stress & Productions & Second syllable & productions & Total \\
\hline Injury & Injury & 16 & In'jury & 0 & 16 \\
Victory & Victory & 16 & Vic'tory & 0 & 16 \\
Luxury & Luxury & 16 & Lu'xury & 0 & 16 \\
Labour & Labour & 16 & La'bour & 0 & 16 \\
\hline
\end{tabular}


The quadri-syllabic "rious" suffixed words (Table 2) bear strong stress on second syllable. Suffixes, "ity" and "rious" have got the effect on shifting the strong stress to antepenultimate (third-from-the-last) syllable in their stems, which means strong stress are placed on the second syllable in, "ity" and "rious" quadri-syllabic stems. All these four stems are "in'jurious" "vic'torious" "lu'xurious" and "la'borious".

Twenty eight first-syllable stress placements were produced in words "victorious" "luxurious" "injurious" and "laborious" by the subjects, which were incorrect stress pattern. The remaining thirty six productions (out of 64 productions) of, "rious" stems were correctly produced on second syllable by the subjects and thus the second-syllable stress was the chief stress pattern in this group of suffixes.

Obviously, the subjects were sensitive to the shift of stress in the "ity" and "rious" stems because the majority of stress placements in their tri-syllabic roots was on the first syllable.

Table 2. Number of productions by the subjects in Quadri-syllabic stems of, "rious" suffixed words, carry second syllable stresses

\begin{tabular}{llllll}
\hline Correct stress & First syllable stress & Productions & Second syllable & productions & Total \\
\hline In'jurious & Injurious & 6 & In'jurious & 10 & 16 \\
Vic'torious & 'Victorious & 4 & Vic'torious & 12 & 16 \\
Lu'xurious & 'Luxurious & 10 & Lu'xurious & 6 & 16 \\
La'borious & 'Laborious & 8 & La'borious & 8 & 16 \\
\hline
\end{tabular}

The "Magistrate" "Delicate" "Intimate" and "Advocate" (table 3) are tri-syllabic root words, carrying primary stress on first syllable. When the suffix "cy" is attached it does not change the stress in syllable because "cy" is stress neutral suffix in English Language. Out of these 64 productions by the subjects in root words, only four incorrect stress placements were produced. Four subjects placed primary stress on second syllable in word "magistrate" which were incorrect production.

The remaining productions of all the primary stress of the roots were placed on first syllable. The first-syllable stress pattern in roots reveals that the subjects were able to stress the first syllable in the root words correctly.

Table 3. Number of productions by the subjects in Tri-syllabic root words, carry first syllable stress

\begin{tabular}{llllll}
\hline Correct stress & First syllable stress & Productions & Second syllable & productions & Total \\
\hline 'Magistrate & 'Magistrate & 12 & Ma'gistrate & 4 & 16 \\
'Delicate & 'Delicate & 16 & De'licate & 0 & 16 \\
'Intimate & 'Intimate & 16 & In'timate & 0 & 16 \\
'Advocate & 'Advocate & 16 & Ad'vocate & 0 & 16 \\
\hline
\end{tabular}

The "Magistracy" "Delicacy" "Intimacy" and "Advocacy" (table 4) are quadri-syllabic suffixed words when the "cy" suffix attaches to these tri-syllabic root words. Out of 64 productions by the subjects, forty stress placements were produced incorrectly. Twenty six accurate first-syllable stress productions is the most dominant pattern in, "cy" stems. Besides, the major pattern of first-syllable stress, there were twenty, second-syllable and eighteen third-syllable stress sharing a comparable production.

The first-syllable stress pattern in roots reveals, that the subjects were able to stress the first syllable in the roots correctly, but they were not capable of placing the main stress on the same syllable in, "tory" and, "cy" suffixed words. Therefore, suffixes, "tory" and, "cy" influence subjects' productions of stress placement.

Table 4. Number of productions by the subjects in Quadri-syllabic stems of, cy suffixed words

\begin{tabular}{llllllll}
\hline Correct stress & first syllable & No & Second syllable & No & third syllable & No & Total \\
\hline 'Magistracy & 'Magistracy & 0 & Ma'gistracy & 8 & Magis'tracy & 8 & 16 \\
'Delicacy & 'Delicacy & 8 & De'licacy & 4 & Deli'cacy & 4 & 16 \\
'Intimacy & 'Intimacy & 10 & In'timacy & 2 & Inti'macy & 4 & 16 \\
'Advocacy & 'Advocacy & 8 & Ad'vocacy & 6 & Ad'vocacy & 6 & 16 \\
\hline
\end{tabular}

The "Reference" "Benefit" "Influence" and "Residence" (table 5) are tri-syllabic root words, bearing strong stress on first syllable but when the suffixes "cial" or "tial" is attached to the roots, the Primary stress is shifted to the 
third syllable in stem words. All these 64 production of the root words were correctly produced. They placed primary stress on first syllable, which was the major stress pattern in these root words.

Table 5. Number of productions by the subjects in Tri-syllabic root words, carry first syllable stress

\begin{tabular}{llllll}
\hline Correct stress & First syllable stress & Productions & Second syllable & productions & Total \\
\hline 'Reference & 'Reference & 16 & Re'ference & 0 & 16 \\
'Benefit & 'Benefit & 16 & Be'nefit & 0 & 16 \\
'Influence & 'Influence & 16 & In'fluence & 0 & 16 \\
'Residence & 'Residence & 16 & Re'sidence & 0 & 16 \\
\hline
\end{tabular}

The quadri-syllabic suffixed words (Table 6) of "cial" and "tial" suffixes bear strong stress on third syllable. Suffixes, "cial" or "tial" and, "ic" shift strong stress to the penultimate (second-from-the-last) syllable, hence third syllable bears the primary stress in quadri-syllabic stems having "cial" or "tial" which are "refe'rential" "bene'ficial" "influ'ential" and "resi'dential".

Out of these 64 productions by the subject, only ten incorrect stress placements were generated. Two subjects placed primary stress on first syllable in word "influential", two placed strong stress on second syllable in word "referential" and six placed on second syllable in word "beneficial", which were incorrect productions.

The distinctive stress patterns of roots and stems demonstrate the awareness of the subjects' change of stress placements when the suffix, "cial" or "tial" is attached to the roots.

Table 6. Number of productions by the subjects in quadri-syllabic stems of, tial/cial suffixed words, carry third syllable stress

\begin{tabular}{llllllll}
\hline Correct stress & first syllable & No & Second syllable & No & third syllable & No & Total \\
\hline Refe'rential & 'Referential & 0 & Re'ferential & 2 & Refe'rential & 14 & 16 \\
Bene'ficial & 'Beneficial & 0 & Be'neficial & 0 & Bene'ficial & 16 & 16 \\
Influ'ential & 'Influential & 2 & In'fluential & 0 & Influ'ential & 14 & 16 \\
Resi'dential & 'Residential & 0 & Re'sidential & 0 & Resi'dential & 16 & 16 \\
\hline
\end{tabular}

The "Pessimist" "Energy" "Paragraph" and "Optimist" (Table 7) are Tri-syllabic root words, carrying primary stress on first syllable. "ic" in English Language is a stress shifting suffix when attached to tri-syllabic root words making them quadri-syllabic suffixed words and shift the strong stress to third syllable of stem words. Out of 64 productions in root words by the subjects, only eight incorrect stress placements were produced in word, "pessimist" and "optimist" where the subjects placed primary stress on second syllable. This is incorrect stress placement in tri-syllabic root words.

Table 7. Number of productions by the subjects in Tri-syllabic root words, carry first syllable stress

\begin{tabular}{llllll}
\hline Correct stress & First syllable stress & Productions & Second syllable & productions & Total \\
\hline 'Pessimist & 'Pessimist & 14 & Pe'ssimist & 2 & 16 \\
'Energy & 'Energy & 16 & E'nergy & 0 & 16 \\
'Paragraph & 'Paragraph & 16 & Pa'ragraph & 0 & 16 \\
'Optimist & 'Optimist & 10 & Op'timist & 6 & 16 \\
\hline
\end{tabular}

"ic" is a stress shifting suffix when attached to tri-syllabic root words making them quadri-syllabic suffixed words (Table 8) bearing strong stress on third syllable. Suffix "ic" shift strong stress to the penultimate (second-from-the-last) syllable, hence third syllable bears the primary stress

Sixty stress placements out of sixty four productions were correctly produced on the third syllable, forming the dominant stress pattern. There are only four stress placements being produced on the second syllable in words "pessimistic" and "optimistic" this was incorrect stress placement produced by the subjects.

The distinctive stress patterns of roots and stems demonstrate the awareness of the subjects' change of stress placements when the suffix, "ic" is attached to the roots words. 
Table 8. Number of productions by the subjects in Quadri-syllabic stems of "ic" suffixed words, carry third syllable stress

\begin{tabular}{llllllll}
\hline Correct stress & first syllable & No & Second syllable & No & third syllable & No & Total \\
\hline Pessi'mistic & 'Pessimistic & 0 & Pe'ssimistic & 2 & Pessi'mistic & 14 & 16 \\
Ener'getic & 'Energetic & 0 & E'nergetic & 0 & Ener'getic & 16 & 16 \\
Para'graphic & 'Paragraphic & 0 & Pa'ragraphic & 0 & Para'graphic & 16 & 16 \\
Opti'mistic & 'Optimistic & 0 & Op'timistic & 2 & Opti'mistic & 14 & 16 \\
\hline
\end{tabular}

The "Tranquil" "complex" "rigid" and "plastic" (Table 9) are bi-syllabic root words. They all carry primary stress on first syllable but when the suffix "ity" attached it produces Quadri-syllabic stem words and the stress is shifted to the second syllable. Out of 64 productions in root words by the subject, eight incorrect stress placements were produced. These eight subjects placed primary stress on second syllable in words "tranquil", which were incorrect production. The rest of the subjects correctly produced the primary stress pattern.

Table 9. Number of productions by the subjects in Bi-syllabic root

\begin{tabular}{llllll}
\hline Correct stress & First syllable stress & Productions & Second syllable & productions & Total \\
\hline 'Tranquil & 'Tranquil & 8 & Tran'quil & 8 & 16 \\
'Complex & 'Complex & 16 & Com'plex & 0 & 16 \\
'Rigid & 'Rigid & 16 & Ri'gid & 0 & 16 \\
'Plastic & 'Plastic & 16 & Plas'tic & 0 & 16 \\
\hline
\end{tabular}

The quadri-syllabic stem words having the suffix, "ity" (Table 10) carry strong stress antepenultimate syllable. Suffix "ity" has an effect on shifting the strong stress to antepenultimate (third-from-the-last) syllable in their stems, which means strong stress are placed on the second syllable in "ity". All the four stems are "tran'quility" "com'plexity" "ri'gidity" and "plas'ticity". In general, the pattern of subjects' stress placement is the second-syllable stress which is also the appropriate strong stress in these stems.

Out of 64 productions in stem words by the subject, only eight incorrect placements were produced by the subjects. These subjects placed primary stress on first syllable in words "plasticity" and "rigidity" which were incorrect production.

Obviously, the subjects are sensitive to the shift of stress in the suffixed words having the suffix "ity" because the majority of stress placements in the bi-syllabic and tri-syllabic roots is on the first syllable.

Table 10. Number of productions by the subjects in Quadri-syllabic stems of, ity suffixed words

\begin{tabular}{llllll}
\hline Correct stress & First syllable stress & Productions & Second syllable & productions & Total \\
\hline Tran'quility & 'Tranquility & 0 & Tran'quility & 16 & 16 \\
Com'plexity & 'Complexity & 0 & Com'plexity & 16 & 16 \\
Ri'gidity & 'Rigidity & 6 & Ri'gidity & 10 & 16 \\
Plas'ticity & 'Plasticity & 2 & Plas'ticity & 14 & 16 \\
\hline
\end{tabular}

"Predator" "Signature" and "Monitors" are tri-syllabic root words carrying primary stress on first syllable, together with "Di'rector" which carry second syllable strong stress (Table 11). Suffixes "tory" along with "cy" in English language are called "stress-neutral" suffixes. The primary stress placed on a syllable in a root word, does not move into another syllable in its suffixed word in words having these suffixes. Out of 64 productions in root words by the subjects, twenty two incorrect stress placements were produced. They placed primary stress on second syllable of these words "predator" and "signature" which were incorrect stress pattern. Apart from the second-syllable stress in "director" and "predator" almost all the primary stress of the roots was placed on first syllable. The first-syllable stress pattern in roots reveals that the subjects were able to stress the first syllable in the roots. 
Table 11. Number of productions by the subjects in Tri-syllabic root words, carry first and second syllable stress

\begin{tabular}{llllll}
\hline Correct stress & First syllable stress & Productions & Second syllable & productions & Total \\
\hline Di'rector & 'Director & 0 & Di'rector & 16 & 16 \\
'Predator & 'Predator & 2 & Pre'dator & 14 & 16 \\
'Signature & 'Signature & 16 & Sig'nature & 0 & 16 \\
'Monitors & 'Monitors & 16 & Mo'nitors & 0 & 16 \\
\hline
\end{tabular}

The quadri-syllabic suffixed words bear primary stress on first and second syllable. Suffixes "tory" along with "cy" in English language are called "stress-neutral" suffixes. The primary stress placed on a syllable in a root word, does not move into another syllable in its suffixed word in words having these suffixes. For example, the words "predator" carries the first-syllable stress and thus "predatory" also bears the strong stress on the first syllable. Seven roots and stems selected in this group carry primary stress and they are "predator" "predatory" "signature" "signatory" "monitor" "monitory" "magistrate" "magistracy" "delicate" "delicacy" "intimate" "intimacy" and "advocate" "advocacy". However, the words "director" "directory" carrying second syllable is chosen for examining whether the subjects would distinguish the different syllables of primary stress between "director" and "predator" (Table 12).

In this group of tory suffixed words, all subjects stressed the second syllable accurately in words "directory" but this stress placement was also found in "predatory" which carry first-syllable stress. The productions of second-syllable stress in "directory" and "predatory" have already occupied half of the thirty two stress placements in "tory" stems. The exact stress pattern shows that the subjects treat the word "director" and "predator" in the same way, so the stress placement of "directory" and "predatory" is identical. Besides this phenomenon, there are ten productions in "signatory" and "monitory" receiving stress on the second syllable, so a total of 42 second-syllable stress were produced out of 64 productions. The remaining productions of "signatory" and "monitory" were all stressed on the first syllable accurately.

Table 12. Number of productions by the subjects in Quadri-syllabic stems of, tory suffixed words, carry first and second syllable stress

\begin{tabular}{llllll}
\hline Correct stress & First syllable stress & Productions & Second syllable & productions & Total \\
\hline Di'rectory & 'Directory & 0 & Di'rectory & 16 & 16 \\
'Predatory & 'Predatory & 0 & Pre'datory & 16 & 16 \\
'Signatory & 'Signatory & 12 & Sig'natory & 4 & 16 \\
'Monitory & 'Monitory & 10 & Mo'nitory & 6 & 16 \\
\hline
\end{tabular}

The "Generous" "Practical" "Uniform" and "Similar" (Table 13) are Tri-syllabic root words, bearing primary stress on first syllable but when the suffix "ity" is attached the stress is shifted to the third syllable in Five-syllabic suffixed words. All the subjects stressed, the words "generous" "practical" "uniform" and "similar" correctly on the first syllable, which is the dominant stress pattern in these root words.

Table 13. Number of productions by the subjects in Tri-syllabic root words, carry first syllable stress

\begin{tabular}{llllll}
\hline Correct stress & First syllable stress & Productions & Second syllable & productions & Total \\
\hline 'Generous & 'Generous & 16 & Ge'nerous & 0 & 16 \\
'Practical & 'Practical & 16 & Prac'tical & 0 & 16 \\
'Uniform & 'Uniform & 16 & U'niform & 0 & 16 \\
'Similar & 'Similar & 16 & Si'milar & 0 & 16 \\
\hline
\end{tabular}

The following Five-syllabic stems of "ity" suffixed words having the suffix "ity" (Table 14) bear strong stress on third syllable. Suffix "ity" has the effect of shifting the word stress to the antepenultimate (third-from-the-last) syllable in a new stem. These four, "ity" suffixed words, "gene'rosity" "practi'cality" "uni'formity" and "simi'larity" carry primary stress on the third syllable.

Out of these 64 productions in stem words by the subject, 14 incorrect stress placements were produced by the subject. Two subjects placed primary stress in words "generosity" first syllable; two subjects placed primary stress on second syllable in "generosity". Two subjects placed primary stress on first syllable in word "practicality" Six subjects placed strong stress on second syllable in word "practicality" while two other subjects placed strong stress 
on fourth syllable in "practicality". These fourteen were incorrect stress productions by the subjects.

Regardless of the syllables bearing the correct stress, all subjects tended to place the primary stress on third syllable while the first-syllable, second-syllable, and the forth-syllable stress were seldom produced. Hence, the third-syllable stress becomes the dominant stress pattern in five-syllable stems.

Table 14. Number of productions by the subjects in Five-syllabic stems of, ity suffixed words, carry third syllable stress

\begin{tabular}{llllllllll}
\hline Correct stress & first syllable & No & Second syllable & No & third syllable & No & Fourth & No & Total \\
\hline Gene'rosity & 'Generosity & 2 & Ge'nerosity & 2 & Gene'rosity & 12 & Genero'sity & 0 & 16 \\
Practi'cality & 'Practicality & 2 & Prac'ticality & 6 & Practi'cality & 6 & Practica'lity & 2 & 16 \\
Uni'formity & 'Uniformity & 0 & U'niformity & 0 & Uni'formity & 16 & Unifo'rmity & 0 & 16 \\
Simi'larity & 'Similarity & 0 & Si'milarity & 0 & Simi'larity & 16 & Simila'rity & 0 & 16 \\
\hline
\end{tabular}

The "Resonate" "Educate" "Con'tribute" and "Contra'dict" (Table 15) are tri-syllabic root words. "Resonate" and "educate" bear strong stress on first syllable respectively, "contribute" bears strong stress on second syllable and the word "contradict" on third syllable. When the suffix "tory" attached to these root words the stress remains neutral and does not shift to other syllable in Five-syllabic stem words.

Out of 64 productions in these root words by the subjects, 34 incorrect stress placements were produced by the subjects. Two incorrect stresses were placed in word "resonate" on second syllable, two stress on third syllable were placed in word "educate" fourteen stress were placed on first syllable in word "contribute". Ten subjects placed primary stress on first syllable in word "contradict" Six subjects placed strong stress on second syllable in word "contradict".

Table 15. Number of productions by the subjects in Tri-syllabic root words, carry first, second and third syllable stress

\begin{tabular}{llllllll}
\hline Correct stress & first syllable & No & Second syllable & No & third syllable & No & Total \\
\hline 'Resonate & 'Resonate & 14 & Re'sonate & 2 & Reso'nate & 0 & 16 \\
'Educate & 'Educate & 14 & E'ducate & 0 & Edu'cate & 2 & 16 \\
Con'tribute & 'Contribute & 14 & Con'tribute & 2 & Contri'bute & 0 & 16 \\
Contra'dict & 'Contradict & 10 & Con'tradict & 6 & Contra'dict & 0 & 16 \\
\hline
\end{tabular}

"Tory" is called neutral suffix, it does not shift the stress when attached to the root words in Five-syllabic stems (table 16). Regardless of the syllables bearing the correct stress, all subjects tended to place the primary stress on third syllable while the first-syllable, second-syllable, and the forth-syllable stress were seldom produced. Hence, the third-syllable stress produced by the subjects was incorrect stress pattern in English words.

Out of 64 these productions in stem words by the subjects, only eighteen correct stress placements were generated. Four correct stresses were placed in word "resonatory" on first syllable, and fourteen subjects correctly placed strong stress on third syllable in word "contradictory" while the remaining were incorrect productions.

Table 16. Number of productions by the subjects in Five-syllabic stems of, tory suffixed words, carry third syllable stress

\begin{tabular}{llllllll}
\hline Correct stress & first syllable & No & Second syllable & No & third syllable & No & Total \\
\hline 'Resonatory & 'Resonatory & 4 & Re'sonatory & 2 & Reso'natory & 10 & 16 \\
'Educatory & 'Educatory & 0 & E'ducatory & 0 & Edu'catory & 16 & 16 \\
Con'tributory & 'Contributory & 0 & Con'tributory & 0 & Contri'butory & 16 & 16 \\
Contra'dictory & 'Contradictory & 2 & Con'tradictory & 0 & Contra'dictory & 14 & 16 \\
\hline
\end{tabular}

\section{Analysis of English Primary Stress Pattern}

\subsection{Stress Pattern of Quadri-Syllabic Stems and their Root Words}

A total of 32 words were divided into six groups of suffixes, these are "cy", "tory", "ity", "rious", "cial" or "tial", and "ic". Each group of suffix consists of four words and they are assigned to three sets of quadri-syllabic stems 
based on the syllable where primary stress is located. In quadri-syllabic stems, suffixes, "cy" and, "tory" do not shift primary stress to other syllable; suffixes "ity" and "rious", shift primary stress to the second syllable; and "cial" or "tial", and "ic" shift primary stress to the third syllable.

\subsubsection{Stress Pattern of Quadri-Syllabic Stems Carrying First-Syllable Stress}

Suffixes "tory" and "cy" in English language are called "stress-neutral" mean the primary stress of a root word does not move to another syllable in its suffixed word, for example, "predator" carries the strong stress on first-syllable in the root word and thus "predatory" also bears the strong stress on the first syllable in suffixed word. Seven roots and stems were selected in this group, which carry primary stress on first syllable. They are "predator" "predatory" "signature" "signatory" "monitor" "monitory" "magistrate" "magistracy" "delicate" "delicacy" "intimate" "intimacy" and "advocate" "advocacy". In these suffixed words, the most dominant stress pattern was the second-syllable stress followed by the first-syllable stress in quadri-syllabic stems produced by the subjects.

A total of 26 correct stress placements were produced out of 64 productions in "tory" suffixed words. In "tory" suffixed words, all the subjects stressed the second syllable accurately in word "directory" but this stress placement was also formed in in other "tory" suffixed words like "predatory" which carries first-syllable stress. The exact stress pattern shows that the subjects treated the "director" and "predator" as the same, hence the stress placements of "directory" and "predatory" is identical. The dominant stress pattern produced by the subjects in "tory" suffixed words by the subjects is second syllable, which is incorrect stress pattern in English Language.

64 "cy" stems consist of a distinctive stress pattern from "tory" stems, the accurate first-syllable stress (26 productions) were the most dominant stress pattern in, "cy" stems. Besides, these major stress pattern of first-syllable stress, there were twenty second-syllable and eighteen third-syllable stress, sharing a comparable production. Although more stress were placed on second syllable in the "cy" stems, the first-syllable stress, which occupies almost half of the productions, is generally the most dominant stress pattern in "cy" suffixed words.

As the primary stress do not shift in the syllable of the "tory" and "cy" root words and their suffixed form, the subjects mostly placed the strong stress on the first syllable in root words but shifted the stress to second and third in suffixed words. Apart from the second-syllable stress in the word, "director" and "predator" almost all the primary stress of the root words were placed on first syllable. The first-syllable stress pattern in root words reveal that the subjects were able to stress the first syllable in the root words correctly, but they were not capable of placing the main stress on the same syllable in, "tory" and, "cy" stems. Therefore, these suffixes, "tory" and, "cy" influence subjects' productions of stress placement.

\subsection{Stress Pattern of Quadri-syllabic Stems, Carrying Second Syllable Stress}

In English language, Suffixes "ity" and "rious" have the effect on shifting the strong stress to antepenultimate (third from the last) syllable in their suffixed word, which means strong stress are placed on the second syllable in "ity" and "rious" quadri-syllabic stems. All the eight stems selected are "tran'quility" "com'plexity" "ri'gidity" "plas'ticity" "in'jurious" "vic'torious" "lu'xurious" and "la'borious". Their root words of "ity" and "rious" are bi-syllabic and tri-syllabic, like "tranquil" "complex" "rigid" "plastic" "injury" "victory" "luxury" and "labor" and they all carry primary stress on first syllable in root words. In general, the pattern of subjects' stress placement was the second-syllable stress, which is the dominant English stress pattern correctly produced.

The subjects were capable of placing the correct primary stress on second syllable in "ity" suffixed words, only eight subjects, placed primary stress on first syllable in words, "rigidity" and "plasticity" incorrectly. In the "rious" quadri-syllabic suffixed words, twenty eight first-syllable stress were produced in words "victorious" "luxurious" "injurious" and "laborious" while the remaining 36 were correctly produced by the participants. A total of 92 correct productions (out of 128 productions) of "ity" and "rious" stems were produced on second syllable by the subjects and thus the second-syllable stress was the chief stress pattern in this group of suffixed words.

Obviously, the subjects were sensitive to the shift of stress in the "ity" and "rious" suffixed words, because the majority of stress placements in these bi-syllabic and tri-syllabic root words was on the first syllable produced by the subjects.

\subsection{Stress Pattern of Quadri-syllabic Stems, Carrying Third-Syllable Stress}

Suffixes "cial" or "tial" and "ic" in English language shift strong stress to the penultimate (second-from-the-last) syllable, that is third syllable bear the primary stress in "cial" or "tial" and "ic" in quadri-syllabic suffixed words. These suffixed words are, "refe'rential" "bene'ficial" "influ'ential" "resi'dential" "pessi'mistic" "ener'getic" "para'graphic" and "opti'mistic". Their root words, "reference" "benefit" "influence" "resident" "pessimist" "energy" "paragraph" and "optimist" carry primary stress on their first syllable. 
These class of suffixed words were more familiar to the subjects, so 120 stress placements out of 128 productions were correctly produced on the third syllable forming the dominant stress pattern. There were only eight stress placements produced on the first or second syllable, two subjects placed strong stress on first syllable and two on second syllable in suffixed words, "influential" "re'ferential" and two placed strong stress on second syllable in word "op'timistic" and two placed on second syllable in word, "pe'ssimistic". Thus, it is strange for eight participants to produce several incorrect stress placements, whereas other subjects are capable of placing the correct primary stress on the third syllable without difficulties.

Same as the root words in previous two groups, the dominant stress pattern of this group of root words is also the first-syllable stress. Only eight subjects out of 128 stressed the second syllable in "pessimist" and "optimist". The distinctive stress patterns of root words and stems demonstrate that the subjects had the awareness of the change of stress placements, when the suffix "cial" or "tial" and "ic" attach to the root words.

\subsection{Stress Pattern of the Five-Syllable Stems and Their Root Words}

Two groups of suffixed words were chosen in five syllabic stems. The suffixation of, "ity" has the effect in English language of shifting the word stress to the antepenultimate (third-from-the-last) syllable in five-syllabic suffixed word, four "ity" suffixed words, they are "gene'rosity" "practi'cality" "uni'formity" and "simi'larity" carry primary stress on the third syllable. As the suffix "tory" has no effect on moving word stress to other syllable, 4 tory suffixed words in this class were also selected like "resonatory" "educatory" "con'tributory" and "contra'dictory".

Although third-syllable stress, which was the dominant stress pattern in "ity" suffixed words. Four of the "ity" suffixed words, bear the third-syllable stress, four-fifth of the subjects' productions on third syllable is correct, that is 14 productions out of 64 . The remaining 50 "ity" suffixed words produced by the subjects were incorrect. In "tory" suffixed words, 0nly eighteen subjects, placed primary stress on first and third syllable correctly, while the remaining "tory" suffixed words, were incorrectly produced by the subjects.

In this study, the dominant stress pattern of the five-syllable stems is on the third-syllable, but their root words generally carry primary stress on the first syllable instead of the third syllable. All the stress in words "generous" "practical" "uniform" and "similar" were placed correctly on the first syllable by all the subjects. Moreover seven-eighth of the root words were stressed on the first syllable that is 52 out of 64, even though "contribute" and "contradict" carry the word stress on the second and the third syllable respectively. "Resonate" and "Educate" are correctly stressed on the first syllable by most of the subjects. Two correct stress placements in word "contribute" were produced. Not a single correct stress was placed in word "contradict" as the entire subject stressed incorrectly.

The stress pattern of the five-syllable suffixed words and their root words indicates that the subjects easily produced the correct stress pattern in "ity" suffixed words and their root words, but they encountered difficulties in stressing the correct syllable in "tory" suffixed words, because all subjects had a tendency to place the primary stress on third syllable in the stems and on first syllable in the roots. It is obvious that there is a big contrast between the five-syllable stems which have a dominant first, second and third syllable stress pattern as the suffix "tory" does not have the effect of shifting stress to other syllable in Five-syllabic stem words.

To conclude, Stress placements continue moving to the second or third syllable when the subjects come across the quadri-syllabic stems. Finally, the third-syllable stress becomes the dominant stress pattern in five-syllable stems. From the above analysis, it is very likely that stress placements of the subjects move from the left to the right when the number of syllables increases in stems.

\subsection{Effect of Suffixes on Primary Stress Placements}

In this part of the analysis, six suffixes are divided into four groups according to their effect on shifting primary stress. Suffixes "ity" and "rious" have the effect of moving word stress to antepenultimate (third from the last) syllables. The suffixes "cial" or "tial" and "ic" attach to the root word, make the stress shift to penultimate (second-from-the-last) syllables, and the last group of suffixes "tory" and "cy" in English Language are called stress-neutral suffixes, in which stress remain unchanged when suffix "tory" or "cy" is added to a root word.

Apart from investigating the effect on subjects' stress placements in stems by the above suffixes, The subjects performed the best in "cial" or "tial" and "ic" suffixed words, as the data show that the number of correct productions vary greatly among different kinds of suffixes. six stems are included in each suffix, However, different number of syllables of words were chosen in each suffix so as to explore if the number of syllables will influence subjects' productions even though the same suffix is attached. For instance, the suffix "ity" consists of four quadri-syllabic stems and four, five-syllable stems, and the suffix "rious" has four quadri-syllabic stems. 


\subsubsection{Stems with the Suffix "tory" and "cy"}

The Suffixes "tory" and "cy" in English language are called, stress-neutral, that means primary stress do not shift to other syllable when the suffixes "tory" or "cy" attach to the root word. The number of incorrect productions by the subjects of these two stress-neutral suffixes is far lower than that of the last-syllable stress-shifting suffixes, but the incorrect stress in suffixed words are (72 out of 192 productions) still occupy, half of the total productions in this group. Compared to their root words, which have fewer syllables, the number of incorrect production of their root words were (34 out of 192 productions) is almost twice the number of wrong production in the suffixed words.

Among the tri-syllabic root words, in this group, only the root word "director" carries a second-syllable stress, while "predator" "signature" and "monitor" bear the first-syllable stress. However, fourteen subjects produced incorrect stress placements on second-syllables as "pre'dator". Therefore, it is not surprising that the subjects produced "pre'datory" stressing the second syllable in "pre'dator". However, there are ten incorrect productions showing incorrect second-syllable stress in suffixed words, "signatory" and "monitory" which should in fact carry first-syllable stress. More evidence will be demonstrated to explore the degree of the effect on the stems by the suffix "tory".

As shown by the data, the dominant stress pattern of "tory" root words is the first-syllable stress, although the correct stress pattern of the root "con'tribute" and "contra'dict" are on the second and the third syllable respectively. The stress pattern of the "tory" suffixed words changes to the third-syllable from the first-syllable stress in five-syllabic stems attached to the root words.

The findings therefore elaborates that the suffix "tory" has a great influence on the stress patterns of the root words and their stems, produced by the subjects, but the change of stress placements increases the number of incorrect productions. It is not necessary to shift the word stress to another syllable in the suffixed word, if the suffix "tory" is attached. However, all subjects changed the stress pattern and formed plenty of wrong productions in this group of suffixed words. It is evident that more inaccurate stress placements were produced in these many-syllabic suffixed words. This is conceivably because the subjects felt unnatural to stress the first or second syllable in long syllabic words.

Similarly in quadri-syllabic suffixed words. More than half of the subjects' productions were incorrect, as strong stress was placed on the second or third syllable in their suffixed words.

While on the other hand, the dominant stress placement of the root words in "magistrate" "delicate" "intimate" and "advocate" was still on the first syllable. All the strong stress were used inappropriately on second or third syllables in word "magistracy" and about half of the stress placements (22 inaccurate stress out of 48 productions) in words like "delicacy" "intimacy" and "advocacy" were also produced incorrectly on second or third syllables. Therefore, the quadri-syllabic suffixed words have more inaccurate shifts of stress placements in suffixed words, which bear a dominant first-syllable stress pattern.

The above analysis of this study demonstrates that English neutral-stress suffixes "tory" and "cy" have a greater consequence on influencing the subjects' productions of the suffixed words, Even though the shift of inappropriate strong stress patterns in "tory" suffixed words occupies half of the total productions in this group of suffixed words, Among these two types of suffixes, the subjects and supposedly Pashto speaking students, who possibly do not have the awareness of shifting stress to other syllable or remain neutral in when the suffix "tory" is attached to the root words and thus more incorrect stress placements were produced.

\subsubsection{Stems with the Suffixes "rious" and "ity"}

These suffixes "rious" and "ity" have the effect of shifting the word stress to antepenultimate (third-from-the-last) syllables. It is evident, that the number of correct productions highly increases compared to the productions of the previous stems by the subjects with suffixes "tory" "cy", there were 148 incorrect stress placements out of 248 total productions in these group of suffixed words.

The dominant stress pattern of these root words was the first-syllable stress and there were only eight incorrect productions in words like "tran'quil" instead of "tranquil". While the remaining stress placements were accurate by all the subjects in root words. For their suffixed words is concerned, strong stress were shifted to second syllables in their quadri-syllabic stems, these suffixed words are "tran'quility" "com'plexity" and third syllables stress in five-syllable suffixed words like "gene'rosity" and "practi'cality".

The data demonstrate that when the suffixes "ity" or "rious" is attached to the root words. The subjects' productions revealed that most of the subjects were aware of the shift of word stress. They place the stress in the correct syllables of the words, without difficulty. However, there were some inaccurate stress placements produced by the subjects, as eight subjects kept on stressing first-syllable in words, "rigidity" and "plasticity" as the 
first-syllable stress in their root words, "rigid" and "plastic". Furthermore, "Practicality" is a suffixed word, being stressed inaccurately on first, second and fourth syllables by eight subjects. It was expected that the first-syllable stress might be produced but there were only four productions showing the exceptions. The large number of shifting in strong stress and correct productions on the part of the subjects, Based on the large number of correctly shifted stress and accurate productions, we can conclude that these suffixes of "ity" has a greater influence on subjects, change of strong stress placements, which enhanced more correct productions, unlike the change of strong stress placements in these suffixes "tory" and "cy" which caused plenty of incorrect productions.

Likewise, the influence of the suffixes "ity" and "rious" on subjects productions was similar, ever since the subjects shift the appropriate word stress in these suffixed words and only 48 strong stress, out of 192 were placed inaccurately by the subjects, with major first-syllable stress. It means that subjects' productions were not easily influenced by the root words, which bear the dominant first-syllable stress pattern. Therefore the influence of these suffixes "ity" and "rious" on the stress placements was different from previous suffixes, like "tory" and "cy".

\subsubsection{Suffixed Words, with the Suffixes "cial" or "tial" and "ic"}

The suffixes "cial" or "tial" and "ic" have the effect of shifting word stress to the penultimate that is second from the last syllables in suffixed words carry stress. These classe of suffixed words receives the highest number of correct stress productions, among all the groups of suffixed words. There were only 16 inaccurate stress placements out of total 256 productions.

Moreover, the suffixed words in these stems like "referential" "beneficial" "influential" and "residential" along with their root words, do not receive many incorrect productions by the subjects. Therefore the data demonstrate that the dominant stress pattern was appropriately produced in third-syllable strong stress by the subjects in the quadri-syllable suffixed words. Commonly, suffixes "cial" and "tial" have a great influence on subjects primary stress placements, that also lead to a large number of correct stress productions as seen in the suffixes "ity".

Whenever, the suffix "ic" attached to the root words, the subjects were also aware of the shift of word stress, as a result only six unusual productions were seen in these words, "pe'ssimistic" and "op'timistic". These productions were very unnatural indeed. Apart from this the subjects correctly shifted the primary stress to third syllables in quadri-syllabic suffixed words. This suffix of "ic" determines a great effect on influencing the subjects production in stress placements and the effect also facilitates in the increase of correct productions.

\section{Conclusion}

The purpose of this research study is to demonstrate the pattern of primary stress produced by Pashto speaking students in different-syllable of root words and their suffixed words, and also to examine the effect of suffixation on learners primary stress placement and the amount of accurate and inaccurate stress placement produced by them.

Irrespective of the correctness of subjects production, the pattern of primary stress in Quadri-syllabic suffixed words was on the second syllable, followed by third syllable stress, which becomes the dominant strong stress pattern in five-syllable suffixed words. It is interesting to ascertain that the dominant pattern of strong stress continue to shift to the right, when the number of syllables increases in a word. In short, all the bi-syllabic and tri-syllabic root words share the same dominant stress pattern of primary stress which is on the first-syllable.

The above analysis advocates that the three types of suffixes in English language assert different degrees of effect on subjects stress placement, which can influence the amount of correct productions by the subjects. Actually, the suffixes "cial" or "tial" and "ic" state a great effect on subjects primary stress placement, because the subjects were capable of generating the shift in primary stress in penultimate syllable. Unlike the greater number of incorrect productions in "tory" and "ity" suffixed words, the subjects were sensitive to the change of stress pattern, which assists a great number of correct productions in "cial" or "tial" and "ic" suffixed words.

This research study does not only assist us to understand the primary stress patterns of root words and their suffixed words, produced by Pashto speaking students, but also demonstrates the effect of suffixation on students' strong stress placements. The awareness of word stress should be aroused so that Pashto speaking students can mend their own deficiency in primary stress placement and henceforth improvement can be made. Also, Khyber Pakhtunkhwa English teachers can also recognize that students encounter difficulty in stressing the correct syllable, therefore they can implement a better teaching way in teaching English word stress instead of only concentrating on the articulation of vowels and consonants. The present study also contributes to further investigation of English word stress and its relationship with suffixation. 


\section{References}

Aitchison, J. (1994). Understanding words. In G. Brown, K. Malmkjor, A. Pollitt, \& J. Williams (Eds.), Language and understanding (pp. 81-96). London: Oxford university press.

Archibald, J. (1998). Second language phonology, phonetics and typology. Studies in Second Language Acquisition, 20, 198-211. https://doi.org/10.1017/S0272263198002046

Archiblad, J. (1998). Second Language Phonology. Amsterdam: Philadelphia, Pa.: J. Benjamins Pub. Co. https://doi.org/10.1075/lald.17

Burzio, L. (1994). Principles of English Stress. New York: Cambridge University Press. https://doi.org/10.1017/CBO9780511519741

Field, J. (2005). Intelligibility and the listener: The role of lexical stress. TESOL Quarterly, 39(3), 399-423. https://doi.org/10.2307/3588487

Fudge, E. (1984). English word-stress. London: Allen \& Unwin.

Giegerich, H. J. (1992). English phonology: an introduction. Cambridge, New York: Cambridge University Press. https://doi.org/10.1017/CBO9781139166126

Gimson, A. C. (1967). An Introduction to the Pronunciation of English. London, UK: Edward Arnold Ltd.

Goës, A. N. (1974). The Stress System of English. Stockholm: K. L. Beckmans Tryckeri.

Guion, S. G., Harada, T., \& Clark, J. J. (2004). Early and late Spanish-English bilinguals' acquisition of English word stress patterns. Bilingualism Language and Cognition, 7, 207-226. https://doi.org/10.1017/S1366728904001592

Hajkr, P. (2000). Comparative Analysis of Czech and English Pronunciation. Pronunciation Mistakes of Czech Speakers. Masaryk University Brno, CZ.

Hill, L. A. (1965). Stress and Intonation. Step by Step. London, UK: Oxford University Press.

Jana, L. (2012). Stress and intelligibility: pronunciation of secondary school students of English. Faculty of Arts, Department of English and American Studies, Masaryk University.

Jones, D. (1976). 50 years in the past and future phonetics and phonology. University College London.

Kingdon, R. (1959). The Groundwork of English Stress. London: Lowe and Brydone.

Nguyen, T. T. A., \& Ingram, J. (2005). Vietnamese Acquisition of English Word Stress. TESOL Quarterly, 39(2), 309-320. https://doi.org/10.1017/S1366728904001592

Nováková, P. (2007). Stress and Rhythm in English and Czech. Masaryk University Brno, CZ.

Plavka, R. (2003). Aspects of English Pronunciation. Havlíčkův Brod, CZ: Fragment.

Poldauf, I. (Ed.) (1984). English word stress: a theory of word-stress patterns in English. Oxford: Pergamon.

Roach, P. (1998). English phonetics and phonology (Vol. 2). New York: Cambridge University press.

Simeon, A. (2013). Some stress placement clues for learners of English as a second Language. British Journal of Arts and Social Sciences.

Skaličková, A. (1974). Srovnávaci fonetika angličtiny a češtiny. Praha, CZ: Academia.

Slowiaczek, L. (1990). Effects of lexical stress in auditory word recognition. Language \& Speech, 33(1), 47-68. https://doi.org/10.1017/S1366728904001592

Tibbitts, E. L. (1967). English Stress Patterns. Cambridge, UK: W. Heffer \& Sons.

Tomková, K. (2008). Perception of Non-Native Pronunciation of English by Native Speakers. (Doctoral dissertation). Masaryk University Brno, CZ.

Tremblay, A. (2008). Prosodic constraints in the acquisition of English primary stress by French Canadian L2 learners. In M. Bowles et al. (Eds.), Proceedings of the 2007 Second Language Research Forum (pp. 158-170). Somerville, MA: Cascadilla Proceedings Project.

Underhill, A. (1994). Sound Foundations. Oxford, UK: Heinemann Ltd.

Weda, S. (2012). Stress shifts of English utterances made by Indonesian speakers of English (ISE). International Journal of English Linguistics, 2(4), 23. https://doi.org/10.5539/ijel.v2n4p23

Wells, J. C. (1971). Practical Phonetics. London, UK: Pitman Publishing. 
Wong, S. P. (1991). The Stress Patterns of Nonsense English Words of Cantonese-Speaking ESL Learners. CUHK Papers in Linguistics.

\section{Copyrights}

Copyright for this article is retained by the author(s), with first publication rights granted to the journal.

This is an open-access article distributed under the terms and conditions of the Creative Commons Attribution license (http://creativecommons.org/licenses/by/4.0/). 